\title{
REPRODUCTIVE TRACT INFECTIONS AMONG MARRIED WOMEN IN RURAL AREA OF HARYANA
}

\author{
Neelu Saluja1, Kajal Jain², D. R. Gaur³, Seema Choudhary4, Seema Sharma ${ }^{5}$, S. M. Pandey 6
}

${ }_{1}^{1}$ Associate Professor, Department of Community Medicine, Maharaja Agrasen Medical College, Agroha.

${ }^{2}$ Associate Professor, Department of Community Medicine, Shri Guru Ram Rai Institute of Medical and Health Sciences, Dehradun.

3 Professor, Department of Community Medicine, Maharaja Agrasen Medical College, Agroha.

${ }^{4}$ Professor, Department of Community Medicine, Maharaja Agrasen Medical College, Agroha.

5 Associate Professor, Department of Community Medicine, Maharaja Agrasen Medical College, Agroha.

${ }^{6}$ Assistant Professor (Stats), Department of Community Medicine, Maharaja Agrasen Medical College, Agroha.

\section{ABSTRACT}

\section{BACKGROUND}

Reproductive tract infections are endemic in developing countries and entail a heavy toll on women. If untreated reproductive tract infections can lead to adverse health outcomes such as infertility, ectopic pregnancy and increased vulnerability to transmission of HIV.

\section{OBJECTIVE}

To assess the magnitude of problem of Reproductive Tract Infections and its socio-demographic correlates among married females in reproductive age group (15-44 years) in rural area of Haryana.

\section{STUDY DESIGN}

Cross-sectional.

\section{PARTICIPANTS}

500 married females in reproductive age group (15-44 yrs).

\section{METHODOLOGY}

The primary tool in this study was predesigned and pretested questionnaire for recording of individual information.

\section{STATISTICAL ANALYSIS}

Percentages and Chi-square.

\section{RESULT}

Out of 500 women interviewed 228 of them were found to be suffering from Reproductive Tract Infections (RTIs) giving a prevalence of $45.6 \%$. Majority of study population belonged to age group of 25-29 years and the prevalence of RTI was maximum $(63.7 \%)$ in the same age group. The prevalence of RTI was significantly higher (56.2\%) in the women belonging to joint families, in women (83.3\%) who were married before 18 years of age, those who were using dirty clothes during menstruation (53.8\%) and in women who adopted IUD's as a means of family planning method (38.8\%). The prevalence of RTI was statistically associated with personal hygiene as the prevalence of RTI was 54.9\%, 46.0\% and 36.0\% in women having poor, fair and good personal hygiene respectively.

\section{CONCLUSION}

Married women in rural Indian community have a high prevalence of RTIs.

\section{KEYWORDS}

Reproductive Tract Infections, Married Women, Correlates, Rural.

HOW TO CITE THIS ARTICLE: Saluja N, Jain K, Gaur DR, et al. Reproductive tract infections among married women in rural area of Haryana. J. Evolution Med. Dent. Sci. 2016;5(14):611-614, DOI: 10.14260/jemds/2016/139

\section{INTRODUCTION}

Reproductive Tract Infections (RTIs) and their complications are among the most important causes of illness and death for women in poor regions of the world. ${ }^{1}$

Financial or Other, Competing Interest: None.

Submission 01-01-2016, Peer Review 28-01-2016,

Acceptance 03-02-2016, Published 16-02-2016.

Corresponding Author:

Dr. Neelu Saluja,

Associate Professor, Department of Community Medicine,

Maharaja Agrasen Medical College,

Agroha, Hisar-125047.

E-mail: neelumd_12@yahoo.com

DOI: $10.14260 /$ jemds/2016/139
The problem is more pronounced in developing and underdeveloped countries where women often have to deal with unwanted pregnancies, unsafe abortions, problems arising from poor contraception practices, different sociocultural norms and lack of economic independence, which further reduce their capacity to protect themselves from RTI/STIs (Sexually transmitted infections). ${ }^{2}$ Reproductive tract infections are endemic in developing countries and entail a heavy toll on women. If untreated reproductive tract infections can lead to adverse health outcomes such as infertility, ectopic pregnancy and increased vulnerability to transmission of HIV. 
It is also associated with adverse pregnancy outcomes. ${ }^{3}$ The prevalence of self-reported RTI symptoms among Indian women has been found to be $11-18 \%$ in national surveys. 4,5 and $40-57 \%$ in various other studies. ${ }^{6,7,8}$ The prevalence of laboratory-diagnosed RTIs ranges from $28 \%$ to $38 \% .9,10$ The present study was carried out to assess the magnitude of problem of RTIs and its socio-demographic correlates among married females of 15-44 years of age group in rural areas of Haryana.

\section{MATERIAL AND METHODS}

This study was conducted with the objective of assessing the magnitude of problem of RTIs and its socio-demographic correlates among married females of reproductive age group of 15-44 years old in a rural area of the district Hisar, Haryana, during December 2009-March 2010. The sample size of 400 was calculated by taking the prevalence of RTIs as $50 \%$ and the permissible level of error as $10 \%$, but to overcome the noncooperation, non-availability and refusal of internal examination a total of 500 married women were covered. All the women who had ever been married in the reproductive age group of 15-44 years old visiting Primary Health Training Centre, Agroha, were interviewed. After taking informed consent, each woman was interviewed in private about her socio-demographic and reproductive history, current and past symptoms affecting the reproductive tract, past sexual behaviour, etc.

They were enquired through oral questionnaire method based on syndromic approach and desired information was collected on pre-designed and pre-tested performa. The performa was pretested by conducting a pilot study in the area. Those having symptoms were examined clinically by per speculum and per vaginal examination after taking their consent. In the study, personal hygiene was categorized as good, fair and poor on the basis of presence of three, two and one or none of the factors respectively of clean skin, clean nails and daily bathing Data analysis was carried out using the Statistical Package for Social Sciences (SPSS) version 16. Chisquare test was used for assessing the significance of association between the women who experienced RTIs and their socio-demographic variables.

\section{RESULTS}

Table 1 shows the relationship between socio-demographic correlates and RTI.

A total of 500 women were interviewed and 228 of them were found to be suffering from RTIs on clinical examination giving a prevalence of $45.6 \%$. Majority of study population belonged to age group of 25-29 years and the prevalence of RTI was maximum (63.7\%) in the same age group followed by 40-44 years $(52.3 \%)$. The difference was statistically significant $\left(\right.$ (? $\left.^{2}=25.185, \mathrm{P}<0.001\right)$.

The prevalence of RTI was significantly higher (56.2\%) in the women belonging to joint families as compared to prevalence in women belonging to nuclear families $(37.9 \%)$. $\left(\mathrm{Q}^{2}=16.370, \mathrm{P}<0.001\right)$

Majority $(69.6 \%)$ of married women had no schooling. The proportion of women who were educated from Ist to VIIIth class and IXth class and above were $16 \%$ and $14.4 \%$ respectively. The prevalence of RTI was $46.0 \%$ and $46.2 \%$ in no schooling and Ist $^{\text {st }}$ VIIIth class educated women respectively as compared to $43.1 \%$ in IX th class and above educated women. ( (? $\left.^{2}=.221, \mathrm{P}=0.895\right)$.

More than twenty percent $(21.6 \%)$ of the women got married under 18 years of age, while $78.4 \%$ got married at 18 years and above. The prevalence of RTI was significantly higher $(83.3 \%)$ in the women who were married before 18 years of age as compared to $35.2 \%$ in women who got married at or after 18 years of age. $\left(0^{2}=79.067, \mathrm{P}<0.001\right)$.

The prevalence of RTI was statistically associated with personal hygiene as the prevalence of RTI was $54.9 \%, 46.0 \%$, and $36.0 \%$, in women having poor, fair and good personal hygiene respectively. $\left(\right.$ ? $\left.^{2}=6.934, \mathrm{P}=0.031\right)$.

The prevalence of RTI was significantly higher $(p<0.001)$ in the women who were using dirty clothes during menstruation (53.8\%) than the prevalence of RTI in women using sanitary pads $(31.9 \%)$ ( (O? $\left.^{2}=22.75, \mathrm{P}<0.001\right)$.

In the present study, $40.8 \%$ females were currently using one or the other contraceptive. The prevalence of RTI was maximum (38.8\%) in women who adopted IUD's as a means of family planning method and minimum (17.5\%) among those using condoms. $(\mathrm{P}<0.001)$.

\begin{tabular}{|c|c|c|c|c|c|}
\hline \multirow{2}{*}{ Factors } & \multirow{2}{*}{ Study Population No. } & \multicolumn{2}{|r|}{ RTI Cases } & \multirow{2}{*}{$\begin{array}{c}2^{2} \\
\text { (df) }\end{array}$} & \multirow{2}{*}{$P$ value } \\
\hline & & No. & Prevalence (\%) & & \\
\hline \multicolumn{6}{|c|}{ 1. Age-wise Distribution } \\
\hline $15-19$ & 42 & 17 & 40.5 & \multirow{6}{*}{$\begin{array}{c}25.19 \\
(5)\end{array}$} & \multirow{6}{*}{$<0.001$} \\
\hline $20-24$ & 62 & 27 & 43.5 & & \\
\hline $25-29$ & 113 & 72 & 63.7 & & \\
\hline $30-34$ & 108 & 38 & 35.2 & & \\
\hline $35-39$ & 110 & 40 & 36.4 & & \\
\hline $40-44$ & 65 & 34 & 52.3 & & \\
\hline \multicolumn{6}{|c|}{ 2. Type of Family } \\
\hline Nuclear & 290 & 110 & 37.9 & \multirow{2}{*}{$\begin{array}{c}16.37 \\
(1)\end{array}$} & \multirow{2}{*}{$<0.001$} \\
\hline Joint & 210 & 118 & 56.2 & & \\
\hline \multicolumn{6}{|c|}{ 3. Women's Education } \\
\hline No schooling & 348 & 160 & 46.0 & \multirow{3}{*}{$\begin{array}{l}.22 \\
(2)\end{array}$} & \multirow{3}{*}{.895} \\
\hline Ist - VIIIth Class & 80 & 37 & 46.2 & & \\
\hline IX ${ }^{\text {th }} \&$ above & 72 & 31 & 43.1 & & \\
\hline \multicolumn{6}{|c|}{ 4. Age at Marriage } \\
\hline Less than 18 years & 108 & 90 & 83.3 & 79.07 & $<0.001$ \\
\hline
\end{tabular}




\begin{tabular}{|c|c|c|c|c|c|}
\hline More than or equal to 18 years & 392 & 138 & 35.2 & (1) & \\
\hline \multicolumn{6}{|c|}{ 5. Personal Hygiene } \\
\hline Good & 100 & 36 & 36.0 & \multirow{3}{*}{$\begin{array}{c}6.93 \\
(2)\end{array}$} & \multirow{3}{*}{.031} \\
\hline Fair & 309 & 142 & 46.0 & & \\
\hline Poor & 91 & 50 & 54.9 & & \\
\hline \multicolumn{6}{|c|}{ 6. Menstrual Hygiene } \\
\hline Use dirty clothes & 312 & 168 & 53.8 & \multirow{2}{*}{$\begin{array}{c}22.75 \\
(1)\end{array}$} & \multirow{2}{*}{$<0.001$} \\
\hline Use Sanitary pads & 188 & 60 & 31.9 & & \\
\hline \multicolumn{6}{|c|}{ 7. Family Planning Methods } \\
\hline Non-users & 296 & 165 & 55.7 & \multirow{6}{*}{$\begin{array}{c}35.64 \\
(3)\end{array}$} & \multirow{6}{*}{$<0.001$} \\
\hline Users & 204 & 63 & 30.9 & & \\
\hline Condoms* & 40 & 7 & 17.5 & & \\
\hline Pills* & 20 & 4 & 20.0 & & \\
\hline IUD & 36 & 14 & 38.8 & & \\
\hline Sterilization & 108 & 38 & 35.2 & & \\
\hline Total & 500 & 228 & 45.6 & & \\
\hline \multicolumn{6}{|c|}{ *Pooled together for calculating $\mathrm{x}^{2}$} \\
\hline \multicolumn{6}{|c|}{ Table 1: Association of Socio-Demographic Variables with RTI } \\
\hline
\end{tabular}

\section{DISCUSSION}

A total of 228 women among the study population had the symptoms suggestive of reproductive tract infections accounting for prevalence of RTI as $45.6 \%$ in married females of 15-44 years, which is similar to $45 \%$ prevalence reported by Prasad JH, et al. ${ }^{9}$ in rural area of Tamil Nadu. Prevalence reported in our study is lower than that reported by Thekdi $\mathrm{KP}$, et al. ${ }^{11}(56.5 \%)$, but much higher than that reported in other studies. ${ }^{12,13,14}$

The prevalence of RTI was significantly associated with age, being maximum in 25-29 years $(63.7 \%)$ followed by $36.5 \%$ in $15-19$ years. In comparison, Pant B, et al.14 also reported a maximum prevalence $(46 \%)$ in $25-29$ years, while Kosambiya et al. ${ }^{15}$ and Sharma et al. ${ }^{16}$ reported maximum prevalence of RTI in 25-34 year age group. Rathore et al. ${ }^{17}$ reported a maximum prevalence of $44.7 \%$ in age group $40-44$ years.

In the present study, the prevalence of RTIs was higher in the women belonging to the joint family (56.2\%) as compared to $37.9 \%$ in women belonging to the nuclear family. This may be on account of ignorance of the symptoms and/or reluctance for the treatment by the females in the joint families.

The prevalence of RTI was $46.0 \%$ and $46.2 \%$ in no schooling and Ist to VIIIth class educated women respectively as compared to $43.1 \%$ in IX ${ }^{\text {th }}$ class and above educated women. Pant Bet al. ${ }^{14}$ also reported lowest prevalence in women educated up to class $9^{\text {th }}$ and above. Rathore et al. ${ }^{17}$ also reported a significantly lower prevalence in women educated above VIIIth class.

The prevalence of RTI was significantly higher (83.3\%) in the women who were married before completing 18 years of age as compared to $35.2 \%$ in 18 years and above age of marriage. Similar findings, i.e. higher prevalence of RTI (40.9\%) among women married at an age below 18 years was also reported by Pant B, et al.14 in her study. Significantly higher prevalence of RTI in females married before completing 18 years of age clearly indicates that early sex and pregnancy increases the risk of infections.

The prevalence of RTI was maximum (54.9\%) in women having poor personal hygiene and minimum (36.0\%) in women having good personal hygiene. A higher prevalence of RTI, i.e. (53.8\%) in women using dirty clothes during menstruation is indicative of poor menstrual hygiene and an added risk for RTI. Low levels of personal hygiene was found to be associated with RTIs in studies by Riyami et al.18 Yang et al. ${ }^{19}$ and Singh $S$ et al. ${ }^{20}$

In our study, the prevalence of RTIs was significantly low in those women who were using condoms (17.5\%). This confirms the well-known fact that contraceptive methods like condoms have a protective role in the prevention of RTI/STI. The prevalence of RTIs was highest in women using IUD's (38.8\%). The increased prevalence of RTI in women using IUD's could be due to the poor follow-up care after insertion. Sharma et al. in. ${ }^{16}$, Mani G et al. ${ }^{12}$, Rathore et al. ${ }^{17}$ and Kumar et al. ${ }^{21}$ have reported similar findings.

\section{CONCLUSION}

Our study shows that RTIs with a prevalence of $45.6 \%$ continues to be a significant problem in rural areas in spite of the various measures adopted by the Indian government to reduce the transmission of RTIs. Age of the women, age of marriage, contraceptive usage practices and personal and menstrual hygiene practices were found to be significantly associated with symptoms of RTIs. Education and outreach are needed to reduce the stigma, embarrassment and lack of knowledge related to RTIs.

\section{RECOMMENDATIONS}

Rural Indian women, especially young women need accurate health education about gynaecologic and reproductive morbidity to reduce the stigma and embarrassment of RTIs. Health services should be improved and made more accessible so that women feel comfortable in seeking treatment and are not deterred by concerns over privacy and confidentiality.

\section{REFERENCES}

1. World Health Organization. Integrating STI/RTI Care for Reproductive health - Sexually Transmitted and Other Reproductive Tract Infections: a guide to essential practice. World Health Organization, 2005. 
2. Jejeebhoy SJ. Addressing women's reproductive health needs: priorities for the family welfare program. Econ Polit Wkly 1997;32:475-484.

3. Kabiru KA, Adewunmi AA, Akinlusi FM, et al. Female reproductive tract infections: understanding and care seeking behaviour among women of reproductive age in Lagos, Nigeria. BMC Women's Health 2010;10

4. International Institute for Population Sciences (IIPS), District Level Household and Facility Survey (DLHS-3), 2007-08, IIPS, Mumbai, India, 2010.

5. IIPS and Macro International, National Family Health Survey (NFHS-3), 2005-06: India, vol. 1, IIPS, Mumbai, India, 2007.

6. Bhanderi $\mathrm{MN}$ and Kannan S. Untreated reproductive morbidities among ever married women of slums of Rajkot City, Gujarat: the role of class, distances, provider attitudes and perceived quality of care. J Urban Health 2010;87(2):254-263.

7. Sudha S, Morrison S and Zhu L. Violence against women, symptom reporting and treatment for reproductive tract infections in Kerala State, Southern India. Health Care Women Int 2007;28(3):268-284.

8. Rani M, Bonu S. Rural Indian women's care-seeking behaviour and choice of provider for gynaecological symptoms. Stud Fam Plann 2003;34(3):173-185.

9. Prasad JH, Abraham S, Kurz KM, et al. Reproductive tract infections among young married women in Tamil Nadu, India. Int Fam Plan Perspect 2005;31(2):73-82.

10. Patel V, Weiss HA, Mabey D, et al. The burden and determinants of reproductive tract infections in India: a population based study of women in Goa, India. Sex Transm I 2006;82(3):243-249.

11. Thekdi KP, Patel KG, Patel NK, et al. A cross-sectional study on the prevalence of reproductive tract infections amongst married women in the rural area of Surendranagar district. Int J Res Med Sci (2014);2(1):215-221.
12. Mani G. Prevalence of reproductive tract infections among rural married women in Tamil Nadu, India: a community based study. J Pioneer Med Sci 2014;4(1):18-24.

13. Singh AJ. Vaginal discharge: its causes and associated symptoms as perceived by rural North Indian women. Indian J Commun Med 2007;32:22-6.

14. Pant B, Singh J, Bhatnagar M, et al. Social correlates in reproductive tract infections. Indian J Commun Med 2008;33(1):52-3.

15. Kosambiya JK, Desai VK, Bhardwaj P, et al. RTI/STI prevalence among urban and rural women of Surat: a community based study. Indian J Sex Transm Dis 2009;30:89-93.

16. Sharma S, Gupta BP. The prevalence of reproductive tract infections and sexually transmitted diseases among married women in the reproductive age group in a rural area. Indian J Commun Med 2009;34:63-65.

17. Rathore Monika, Swami SS, Gupta BL, et al. Community based study of self-reported morbidity of reproductive tract among women of reproductive age in rural area of Rajasthan. Indian J Commun Med 2003;28(3):117-121.

18. Riyami AL, Afifi M, Fathulla MMF. Gynaecological and related morbidity among ever-married Omani women. African J Reprod Health 2004;8:188-197.

19. Yang LR, Zhao H, Wang HP, et al. Improving ability of married women to prevent reproductive tract infections in Rural Western China. Environ Health Prev Med 2006;11:233-240.

20. Singh S, Kandpal SD, Roy D. Menstrual hygiene practices and RTI among ever married women in rural slum. Indian J Community Health 2011;22:41-43.

21. Kumar S, Gupta SD, Kumar D, et al. Reproductive tract infections and their associated risk factors among the women in Bundi District of Rajasthan. J Hum Ecol 2002;13:307-310. 